Necropolítica no Estado do Rio de Janeiro.

Revista Ensaios, vol. 15, jul-dez de 2019.

\title{
Necropolítica no Estado do Rio de Janeiro
}

\author{
Ítalo do Couto Ferreira ${ }^{1}$
}

\begin{abstract}
Resumo: A presente pesquisa visou analisar a eficiência e a eficácia da política de morte, ou necropolítica, adotada como política de segurança pública pelo governador do Estado do Rio de Janeiro, Wilson Witzel. Para tal, foi testada estatisticamente a relação entre o aumento dos homicídios por intervenção policial e a diminuição dos homicídios dolosos, compilando-se dados dessas variáveis do primeiro semestre de 1998 até o primeiro semestre de 2019, constatando-se que não existe evidência estatística que comprove essa relação entre as variáveis. Qualitativamente, analisou-se o discurso de morte do governador à luz da Necropolítica, de MBEMBE (2016), e da filosofia dos direitos humanos aplicada à atuação policial, demonstrando que essa política e discurso de morte, ilegalmente, submete os moradores das favelas fluminenses a um estado de exceção, que mata, desumaniza e fere a dignidade da pessoa humana. Além disso, à luz do direito internacional e nacional, foi demonstrado que a necropolítica adotada pelo governo Witzel infringe os tratados de direitos humanos e as leis nacionais quanto ao uso da força por policiais, sobretudo, utilizando armas de fogo.
\end{abstract}

Palavras-chave: Necropolítica, Polícia, Direitos Humanos, Homicídio, Segurança Pública.

\section{Necropolitics in the State of Rio de Janeiro}

Abstract: This research aimed to analyze the efficiency and effectiveness of the death policy, or necropolitics, adopted as a public security policy by Rio de Janeiro State Governor Wilson Witzel. To this end, the relationship between the increase in homicides by police intervention and the decrease in intentional homicides was statistically tested, compiling data on these variables from the first semester of 1998 to the first semester of 2019. prove this relationship between the variables. Qualitatively, the governor's death discourse was analyzed in the light of MBEMBE's Necropolitics (2016), and the human rights philosophy applied to police action, demonstrating that this policy and death discourse illegally submits residents of Rio de Janeiro's favelas. to a state of exception that kills, dehumanizes and hurts the dignity of the human person. In addition, in the light of international and national law, it has been shown that the necropolitics adopted by the Witzel administration contravene human rights treaties and national laws regarding the use of force by police officers, especially using firearms.

Keywords: Necropolitics, Police, Human Rights, Homicide, Public Security.

\footnotetext{
${ }^{1}$ Capitão PM Reformado, graduado no Curso de Formação de Oficiais (APM/PMERJ). MBA Executivo: Marketing (EBAPE/FGV). Especialista em Planejamento, Implementação e Gestão da Educação a Distância (UFF). Especialista em Gestão em Administração Pública (UFF). Especialista em Gestão em Segurança Corporativa (AVM). Especialista em Políticas Públicas de Justiça Criminal e Segurança Pública (UFF). Especialista em Segurança e Cidadania (CESeC/UCAM). Também possui graduação em Administração (UFF).
} 
Necropolítica no Estado do Rio de Janeiro.

Revista Ensaios, vol. 15, jul-dez de 2019.

Atualmente, segundo projeção do Instituto Brasileiro de Geografia e Estatística (IBGE), o Estado do Rio de Janeiro (RJ) tem 17.272.695 habitantes. De acordo com Meirelles e Athayde (2014), 22\% da população do RJ mora em favela, ou seja, 3.799.993 pessoas. Conforme os supracitados autores, a renda média dessa população é de $\mathrm{R} \$$ 965,00 e tem o seguinte nível de instrução educacional: 3\% não são instruídos; 27\% possuem ensino médio; $4 \%$ possuem ensino superior incompleto; e $1 \%$ possui ensino superior. Os autores ainda afirmam que, dos moradores das favelas: 67\% são negros, $42 \%$ dos lares são chefiados por mulheres; $52 \%$ já passaram fome; $60 \%$ já foram vítimas de preconceito. Apesar disso, Meirelles e Athayde (2014) afirmam que os moradores das favelas são atuantes no mercado consumidor e geram riqueza. Segundo Belo (2015), o consumo de moradores de favelas no Brasil supera $\mathrm{R} \$ 68$ bilhões ao ano.

Aparentemente, o Governo do Estado do Rio de Janeiro, na figura do seu governador, Wilson Witzel - que é o Comandante-Chefe das polícias civil e militar, conforme o $\S 6^{\circ}$ do artigo 144 da Constituição Federal (BRASIL, 1988) -, ignora a relevância das favelas e de seus moradores na constituição da sociedade fluminense ao concentrar as suas políticas de segurança pública sobre essa população, ou seja, resta-lhes um Estado Policial, não um Estado de Direito, uma vez que as polícias parecem ser os únicos órgãos estatais atuantes nas favelas. Essa política de controle policial contundente nas favelas se torna visível nos discursos do governador, como: "O correto é matar o bandido que está de fuzil. A polícia vai fazer o correto: vai mirar na cabecinha e... fogo! Para não ter erro." (VEJA, 2018); "Se tiver de arma na mão, tem que morrer." (O GLOBO, 2018); "Não se combate o terrorismo com flores." (TV BRASIL, 2019); "Se fosse com autorização da ONU, em outros lugares do mundo, nós teríamos autorização para mandar um míssil naquele local e explodir aquelas pessoas" (O GLOBO, 2019), disse o governador Wilson Witzel sobre explodir traficantes na favela Cidade de Deus; e "Não sai de fuzil na rua não, troca por uma Bíblia, porque, se você sair, nós vamos te matar." (NA LATA, 2019). Embora o governador não especifique quem são os criminosos armados, é sabido e notório que narcotraficantes e milicianos que atuam em favelas são os principais criminosos usuários de arma de fogo, inclusive fuzis, no Estado do Rio de Janeiro. Assim, 22\% da população do RJ mora na zona de confronto entre as polícias e os bandidos, ou seja, nas favelas, e estão sujeitas a serem vitimadas no meio 
desse confronto, o chamado "efeito colateral", como foi o caso de seis jovens inocentes mortos, durante ações policiais, em cinco dias (G1, 2019). De acordo com Abdala (2011), a Comissão de Direitos Humanos da Assembleia Legislativa do Estado do Rio de Janeiro (Alerj) denunciou o governador Wilson Witzel à Organização de Estados Americanos (OEA), devido à política para a área de segurança pública, baseada em crimes contra a humanidade, pena de morte e tortura, que contrariam a Constituição Federal (BRASIL, 1988).

Tal política de segurança pública, baseada em uma política de morte, tem sido posta em prática pelo Governo do Estado do Rio de Janeiro, já que, segundo Mello (2019), o primeiro semestre do governo Witzel bateu o recorde de mortes registradas em decorrência de confronto contra agentes de segurança pública. Foram 881 mortes, representando $30 \%$ das mortes violentas no estado no período de referência, com média de uma morte a cada cinco horas. Essa estatística representa um aumento de 14,5\% nos homicídios decorrentes de intervenção policial em comparação com o primeiro semestre de 2018 (769 mortes) e é a maior quantidade de mortes dessa modalidade registrada desde que os órgãos estatais começaram a compilar esses casos, em 1998 (MELLO, 2019). Contudo, Mello (2019) também afirma que, no primeiro semestre de 2019, houve queda de $22,6 \%$ nos registros de homicídios dolosos em relação a 2018, atingindo o menor patamar desde 1991.

Diante desses fatos, a presente pesquisa visa responder a seguinte questão: A necropolítica adotada como política de segurança pública, pelo governador Wilson Witzel, é eficaz na redução de homicídios dolosos no Estado do Rio de Janeiro?

\section{1) A necropolítica:}

Na obra de Michel Foucault (2005), biopolítica é o estilo de governo que regulamenta a população por meio do biopoder. Em seus domínios, não está mais em jogo o direito de vida e de morte sobre os indivíduos, que caracteriza a teoria clássica da soberania e que concretamente se traduz em fazer morrer e deixar viver. Na biopolítica, a vida é o objeto de agenciamento do poder, onde a época moderna opõe, ao velho direito de morte e vida da soberania, um outro direito, o poder de fazer viver e deixar morrer. 
Necropolítica no Estado do Rio de Janeiro.

Revista Ensaios, vol. 15, jul-dez de 2019.

Aquille Mbembe diz que:

[...] a expressão máxima da soberania reside, em grande medida, no poder e na capacidade de ditar quem pode viver e quem deve morrer. Por isso, matar ou deixar viver constituem os limites da soberania, seus atributos fundamentais. Exercitar a soberania é exercer controle sobre a mortalidade e definir a vida como a implantação e manifestação de poder. (MBEMBE, 2016, p. 123).

Ser soberano é controlar a mortalidade e estabelecer a vida como a manifestação e implantação de poder. Assim, a soberania é a capacidade de determinar quem não importa e quem importa, quem é descartável e quem não é. A guerra, além de uma forma de alcançar a soberania política, também é um meio de exercer o direito de matar (MBEMBE, 2016).

Mbembe (2016) rejeita a crença romântica da soberania como algo no qual o principal autor controlador do seu próprio significado é o sujeito. Sob uma ótica completamente diferente, o supracitado autor preocupa-se com as formas de soberania nas quais o projeto central não é a luta pela soberania, mas sim a instrumentalização geral da existência humana e a destruição material de corpos humanos e populações. Assim, o autor segue criticando o discurso filosófico da modernidade, afirmando que das experiências contemporâneas de destruição humana, pode-se extrair uma leitura da política, da soberania e do sujeito, considerando "[...] outras categorias fundadoras menos abstratas e mais táteis, tais como a vida e a morte.” (MBEMBE, 2016, p. 125).

Mbembe (2016) relaciona a noção foucaultiana de biopoder (FOUCAULT, 2005) com outros dois conceitos, o estado de exceção e o estado de sítio (AGAMBEN, 1995 apud MBEMBE, 2016), e mostra como “[...] o estado de exceção e a relação de inimizade tornaram-se a base normativa do direito de matar" (MBEMBE, 2016, p. 128), e como o poder '[...] apela à exceção, emergência e a uma noção ficcional do inimigo" (MBEMBE, 2016, p. 128) a fim de justificar o extermínio de outrem. A partir desse ponto de vista, Mbembe considera que a escravidão "[...] pode ser considerada uma das primeiras instâncias da experimentação biopolítica” (MBEMBE, 2016, p. 130), motivo pelo qual qualquer "[...] relato histórico do surgimento do terror moderno precisa tratar da escravidão" (MBEMBE, 2016, p. 130). Para o supracitado autor, a condição de escravo “[...] resulta de uma tripla perda: perda de um 'lar', perda de direitos sobre seu corpo e perda de status político. Essa perda tripla equivale a dominação absoluta, alienação ao 
Necropolítica no Estado do Rio de Janeiro.

Revista Ensaios, vol. 15, jul-dez de 2019.

nascer e morte social (expulsão da humanidade de modo geral).” (MBEMBE, 2016, p. 131). Desse modo, o escravo “[...] é mantido vivo, mas em 'estado de injúria', em um mundo espectral de horrores, crueldade e profanidade intensos." (MBEMBE, 2016, p. 131). Logo, a vida do escravo é uma forma de morte em vida e propriedade do seu senhor (MBEMBE, 2016). Sob essa perspectiva de colonização, Mbembe entende que:

[...] as colônias são semelhantes às fronteiras. Elas são habitadas por "selvagens". As colônias não são organizadas de forma estatal e não criaram um mundo humano. Seus exércitos não formam uma entidade distinta, e suas guerras não são guerras entre exércitos regulares. Não implicam a mobilização de sujeitos soberanos (cidadãos) que se respeitam mutuamente, mesmo que inimigos. Não estabelecem distinção entre combatentes e não combatentes ou, novamente, "inimigo" e "criminoso". Assim, é impossível firmar a paz com eles. Em suma, as colônias são zonas em que guerra e desordem, figuras internas e externas da política, ficam lado a lado ou se alternam. Como tal, as colônias são o local por excelência em que os controles e as garantias de ordem judicial podem ser suspensos - a zona em que a violência do estado de exceção supostamente opera a serviço da "civilização". (MBEMBE, 2016, p. 133).

Aqui, podemos observar, na visão de Foucault (2009), o segundo modo de objetivação que transforma os seres humanos em sujeitos, no que ele chama de "práticas divisoras" (FOUCAULT, 2009, p. 231), no qual o "[...] sujeito é dividido no seu interior e em relação aos outros. Este processo o objetiva. Exemplos: o louco e o são, o doente e o sadio, os criminosos e os 'bons meninos'." (FOUCAULT, 2009, p. 231). Assim, aos olhos do conquistador '[...] 'vida selvagem' é apenas outra forma de 'vida animal', uma experiência assustadora, algo alienígena além da imaginação ou compreensão." (MBEMBE, 2016, p. 133). Daí, o autor chega à conclusão de que da "[...] negação racial de qualquer vínculo comum entre o conquistador e o nativo provém a constatação de que as colônias possam ser governadas na ilegalidade absoluta." (MBEMBE, 2016, p. 133). Para ilustrar isso, Mbembe cita o caso palestino como a '[...] forma mais bem sucedida de necropoder [...]" (2016, p. 136) quando diz que:

Populações inteiras são o alvo do soberano. As vilas e cidades sitiadas são cercadas e isoladas do mundo. O cotidiano é militarizado. É outorgada liberdade aos comandantes militares locais para usar seus próprios critérios sobre quando e em quem atirar. (MBEMBE, 2016, 138).

Essa população sitiada experimenta “[...] uma condição permanente de 'estar na dor': estruturas fortificadas, postos militares e bloqueios de estradas em todo lugar [...]" (MBEMBE, 2016, p. 146), que nos faz lembrar o exercício do poder que caracteriza o próprio Estado que, segundo Elias (2006), é baseado no monopólio do uso legítimo da violência física e dos meios de tributação. 
Necropolítica no Estado do Rio de Janeiro.

Revista Ensaios, vol. 15, jul-dez de 2019.

Embora o governo Witzel faça uso do discurso de morte e tenha intensificado a política de enfrentamento policial aos narcotraficantes nas favelas fluminenses, cabe ressaltar que essa prática já era frequente nas polícias do RJ, uma vez que:

[...] se estabeleceu como legítima uma prática de mortes por parte do Estado, que, entre 2001 a 2011, como demonstram dados do Instituto de Segurança Pública, matou mais de 10 mil pessoas. A maioria dessas mortes ocorreu nas favelas da cidade do Rio de Janeiro [...] (EILBAUM; MEDEIROS, 2014, p. 412-413).

Para ser mais exato, segundo dados do Instituto de Segurança Pública (ISP), no período de 2001 ao final de 2011, foram registrados 10.724 homicídios por intervenção policial. Desde que o Estado começou a contabilizar essa modalidade de homicídio, de janeiro de 1998 até junho de 2019, foram registrados 18.326 homicídios. Vide a Tabela 1.

Tabela 1 - Série histórica semestral de homicídios de 1998 até o $1^{\circ}$ semestre de 2019.

\begin{tabular}{|c|c|c|}
\hline Período & Homicídio por intervenção policial & Homicídio doloso \\
\hline $1998\left(1^{\circ}\right.$ semestre $)$ & 196 & 3105 \\
\hline $1998\left(2^{\circ}\right.$ semestre $)$ & 159 & 2621 \\
\hline $1999\left(1^{\circ}\right.$ semestre $)$ & 147 & 3026 \\
\hline $1999\left(2^{\circ}\right.$ semestre $)$ & 142 & 2862 \\
\hline $2000\left(1^{\circ}\right.$ semestre $)$ & 172 & 3287 \\
\hline $2000\left(2^{\circ}\right.$ semestre $)$ & 255 & 3000 \\
\hline $2001\left(1^{\circ}\right.$ semestre $)$ & 300 & 3151 \\
\hline $2001\left(2^{\circ}\right.$ semestre $)$ & 292 & 3012 \\
\hline $2002\left(1^{\circ}\right.$ semestre $)$ & 409 & 3570 \\
\hline $2002\left(2^{\circ}\right.$ semestre $)$ & 491 & 3315 \\
\hline $2003\left(1^{\circ}\right.$ semestre $)$ & 621 & 3515 \\
\hline $2003\left(2^{\circ}\right.$ semestre $)$ & 574 & 3109 \\
\hline $2004\left(1^{\circ}\right.$ semestre $)$ & 469 & 3268 \\
\hline $2004\left(2^{\circ}\right.$ semestre $)$ & 514 & 3170 \\
\hline $2005\left(1^{\circ}\right.$ semestre $)$ & 501 & 3483 \\
\hline $2005\left(2^{\circ}\right.$ semestre $)$ & 597 & 3137 \\
\hline $2006\left(1^{\circ}\right.$ semestre $)$ & 520 & 3210 \\
\hline $2006\left(2^{\circ}\right.$ semestre $)$ & 543 & 3113 \\
\hline $2007\left(1^{\circ}\right.$ semestre $)$ & 694 & 3135 \\
\hline $2007\left(2^{\circ}\right.$ semestre $)$ & 636 & 2998 \\
\hline $2008\left(1^{\circ}\right.$ semestre $)$ & 757 & 2859 \\
\hline $2008\left(2^{\circ}\right.$ semestre $)$ & 380 & 2858 \\
\hline $2009\left(1^{\circ}\right.$ semestre $)$ & 561 & 3198 \\
\hline $2009\left(2^{\circ}\right.$ semestre $)$ & 487 & 2595 \\
\hline $2010\left(1^{\circ}\right.$ semestre $)$ & 505 & 2552 \\
\hline $2010\left(2^{\circ}\right.$ semestre $)$ & 350 & 2215 \\
\hline $2011\left(1^{\circ}\right.$ semestre $)$ & 372 & 2252 \\
\hline $2011\left(2^{\circ}\right.$ semestre $)$ & 151 & 2027 \\
\hline $2012\left(1^{\circ}\right.$ semestre $)$ & 216 & 2124 \\
\hline Período & Homicídio por intervenção policial & Homicídio doloso \\
\hline $2012\left(2^{\circ}\right.$ semestre $)$ & 203 & 1957 \\
\hline $2013\left(1^{\circ}\right.$ semestre $)$ & 200 & 2406 \\
\hline
\end{tabular}


Necropolítica no Estado do Rio de Janeiro.

Revista Ensaios, vol. 15, jul-dez de 2019.

\begin{tabular}{|c|c|c|}
\hline $2013\left(2^{\circ}\right.$ semestre $)$ & 216 & 2339 \\
\hline $2014\left(1^{\circ}\right.$ semestre $)$ & 287 & 2726 \\
\hline $2014\left(2^{\circ}\right.$ semestre $)$ & 297 & 2216 \\
\hline $2015\left(1^{\circ}\right.$ semestre $)$ & 349 & 2105 \\
\hline $2015\left(2^{\circ}\right.$ semestre $)$ & 296 & 2095 \\
\hline $2016\left(1^{\circ}\right.$ semestre $)$ & 400 & 2472 \\
\hline $2016\left(2^{\circ}\right.$ semestre $)$ & 525 & 2570 \\
\hline $2017\left(1^{\circ}\right.$ semestre $)$ & 580 & 2731 \\
\hline $2017\left(2^{\circ}\right.$ semestre $)$ & 547 & 2615 \\
\hline $2018\left(1^{\circ}\right.$ semestre $)$ & 769 & 2691 \\
\hline $2018\left(2^{\circ}\right.$ semestre $)$ & 765 & 2259 \\
\hline $2019\left(1^{\circ}\right.$ semestre $)$ & 881 & 2083 \\
\hline Total & $\mathbf{1 8 . 3 2 8}$ & $\mathbf{1 1 9 . 0 3 2}$ \\
\hline Elabsi
\end{tabular}

Fonte: Elaboração própria (2019), utilizando dados do ISP. Disponível em: http://www.ispdados.rj.gov.br/estatistica.html. Acesso em: 11 ago. 2019.

\section{2) Filosofia dos Direitos Humanos aplicada à atuação policial:}

A proteção dos direitos fundamentais da pessoa humana visa, em favor da pessoa humana, limitar e controlar os abusos cometidos pelo Estado e suas autoridades constituídas. Atualmente, a proteção dos direitos fundamentais da pessoa humana se instrumentaliza por meio de tratados internacionais e de legislação nacional. Nesse contexto, para fortalecer e aprimorar o grau de proteção dos direitos consagrados, usa-se o direito internacional (SENASP, 2017).

O direito internacional público:

[...] consiste no corpo de regras que governam as relações entre os Estados, mas compreende também normas relacionadas ao funcionamento de instituições ou organizações internacionais, a relação entre elas e a relação delas com o Estado e os indivíduos. (SENASP, 2017, p. 5, grifo do autor).

O Direito Internacional Humanitário (DIH) e o Direito Internacional dos Direitos Humanos (DIDH) regulam vários aspectos do direito internacional e incluem regras sobre: os direitos de território dos Estados, ou seja, relativas à terra, mar e espaço aéreo; o comércio internacional; a proteção do meio ambiente; e o uso da força pelos Estados (SENASP, 2017).

O DIH é o “[...] conjunto de normas cuja finalidade, em tempo de conflito armado, é por um lado, proteger as pessoas que não participam, ou que deixaram de participar nas hostilidades, e por outro, limitar os meios e métodos de fazer a guerra." (SENASP, 
Necropolítica no Estado do Rio de Janeiro.

Revista Ensaios, vol. 15, jul-dez de 2019.

2017, p. 7, grifo do autor), também é conhecido como Direito de Guerra ou Direito dos

Conflitos Armados (SENASP). O DIH é aplicado nas seguintes situações:

- Em um conflito armado internacional: conflito armado entre Estados (inclusive se não houver sido declarada guerra formalmente, ou mesmo se não há atividades militares);

- Quando a totalidade do território de um Estado ou parte desse tenha sido ocupado (inclusive se não tiver havido resistência armada a essa ocupação);

- Quando povos lutam contra a dominação colonial, contra ocupação estrangeira ou contra regimes racistas, no exercício de seu direito à livre determinação;

- Em um conflito armado não internacional: conflito armado que se desenvolve dentro do território de um Estado, e se as forças armadas de outro Estado não participam das operações militares. (SENASP, 2017, p. 8 , grifo nosso).

O DIH não é aplicado às situações consideradas de violência menor, que podem ser classificados como tensões internas ou distúrbios, tais como supressão de: passeatas; motins; manifestações violentas; reuniões violentas; desordens e atos de violência análogos. Em tais casos, aplica-se a legislação nacional (SENASP, 2017).

Segundo Rover (2005), as situações de conflito armado são um produto da deterioração do estado da lei e da ordem em um país, nos quais as organizações de aplicação da lei possuem responsabilidade direta.

Pela natureza dos deveres do trabalho policial, e o envolvimento prático desses agentes na resolução de conflitos que podem acarretar combates armados, requer-se que os policiais integrem os princípios de DIH e direitos humanos em seus treinamentos e operações (SENASP, 2017). Os princípios básicos do Direito Humanitário são:

- Trato Humano e não discriminação: toda pessoa deve ser tratada com humanidade e sem discriminação (sexo, nacionalidade, raça, crença religiosa ou política). Ex: os que estão fora de combate (combatentes que se renderam, feridos, enfermos, náufragos, prisioneiros de guerra), detidos, pessoas civis, pessoal sanitário e religioso.

- Necessidade Militar: toda atividade de combate deve justificar-se por motivos militares; estão proibidas as atividades que não sejam militarmente necessárias. São aquelas não proibidas pelo Direito Humanitário e necessárias para derrotar o inimigo. Deve ser analisada juntamente com os princípios de distinção e proporcionalidade.

- Limitação: as armas e os métodos de guerra que podem ser utilizados são limitados. Estão proibidas as armas que causem sofrimentos desnecessários ou danos supérfluos. Ex: estão proibidas aquelas que causem ferimentos de impossível tratamento ou que causem morte lenta e cruel. 
Necropolítica no Estado do Rio de Janeiro.

Revista Ensaios, vol. 15, jul-dez de 2019.

\begin{abstract}
- Distinção: deve-se distinguir entre combatentes e não combatentes. Deve-se também distinguir entre objetivos militares (que podem ser atacados) e bens de caráter civil (que não podem ser atacados).

- Proporcionalidade: quando são atacados objetivos militares, as pessoas civis e os bens de caráter civil devem ser preservados o melhor possível de danos colaterais. Não devem ser excessivos os danos colaterais com respeito à vantagem militar direta e concreta esperada de qualquer ataque contra um objetivo militar.
\end{abstract}

- Boa fé: deve prevalecer a boa fé nas negociações entre as partes beligerantes. (SENASP, 2017, p. 9, grifo do autor).

Por isso, determinado nível de conhecimento do DIH é indispensável aos policiais para o correto desempenho de suas atividades. O DIH está dividido no Direito de Genebra $^{2}$ e no Direito de Haia ${ }^{3}$. O Brasil ratificou todas as quatro Convenções de Genebra em 29 de junho de 1957, bem como dois Protocolos adicionais em 05 de maio de 1992. Além disso, o Brasil ratificou três Convenções de Haia, respectivamente em 27 de fevereiro de 1973, 03 de outubro de 1995 e 30 de abril de 1999 (SENASP, 2017).

O Direito Internacional dos Direitos Humanos (DIDH) pode ser definido como um "[...] conjunto de princípios e regras, com base nas quais os indivíduos ou grupos de indivíduos podem esperar certa qualidade minimamente desejável de comportamento da parte das autoridades, somente em virtude de serem seres humanos." (SENASP, 2017, p. 12).

O preâmbulo da Declaração Universal dos Direitos Humanos (DUDH), adotada pela Organização das Nações Unidas (ONU), em 1948, diz que o:

(...) reconhecimento da dignidade inerente e ... direitos iguais e inalienáveis a todos os membros da família humana constituem o fundamento da liberdade, da justiça e da paz no mundo ... o desconhecimento e o desprezo dos direitos humanos conduziram a atos de barbárie ... é essencial a proteção dos direitos do homem através de um estado de direito, para que o homem não seja compelido, em supremo recurso, à revolta contra a tirania e a opressão (...) (SENASP, 2017, p. 12).

\footnotetext{
${ }^{2}$ O Direito de Genebra trata da proteção das vítimas de guerra, sejam elas militares ou civis, na água ou em terra. Protege todas as pessoas fora de combate, isto é, que não participam ou não estão mais participando nas hostilidades: os feridos, os doentes, os náufragos e os prisioneiros de guerra. (SENASP, 2017, p. 9, grifo do autor).

${ }^{3} \mathrm{O}$ direito de Haia preocupa-se mais com a regulamentação dos métodos e meios de combate, e concentrase na condução das operações militares. O direito de Haia é, portanto, de interesse fundamental ao comandante militar em terra, mar e ar. (SENASP, 2017, p. 10, grifo do autor).
} 
Necropolítica no Estado do Rio de Janeiro.

Revista Ensaios, vol. 15, jul-dez de 2019.

A partir da contextualização do preâmbulo da DUDH, pode-se explicar o papel que os policiais devem exercer para proteger e promover os direitos humanos. Os policiais devem compreender como o DIDH afeta o seu exercício profissional (SENASP, 2017).

A Carta Internacional dos Direitos Humanos é uma referência coletiva a três importantes instrumentos dos Direitos Humanos: Declaração Universal dos Direitos do Homem (DUDH), assinada pelo Brasil em 10 de dezembro de 1948; Pacto Internacional sobre os Direitos Civis e Políticos (PIDCP), ratificado pelo Brasil em 24 de janeiro de 1992; Pacto Internacional sobre os Direitos Econômicos, Sociais e Culturais (PIDESC), ratificado em 24 de abril de 1992 (SENASP, 2017). Também, os seguintes tratados sobre Direitos do Homem são importantes: Convenção sobre a Prevenção e Repressão do Crime de Genocídio, ratificada pelo Brasil em 06 de maio de 1952; Convenção Internacional sobre a Eliminação de Todas as Formas de Discriminação Racial, ratificada pelo Brasil em 27 de março de 1968; Convenção sobre a Eliminação de Todas as Formas de Discriminação contra as Mulheres, ratificada pelo Brasil em 01 de fevereiro de 1984; Convenção contra a Tortura e Outras Penas ou Tratamentos Cruéis, ratificada pelo Brasil em 28 de setembro de 1989; Convenção sobre os Direitos da Criança, ratificada pelo Brasil em 24 de setembro de 1990; Convenção Relativa ao Estatuto dos Refugiados, ratificada pelo Brasil em 15 de novembro de 1960; Protocolo Facultativo ao Estatuto dos Refugiados, aderido pelo Brasil em 07 de abril de 1992 (SENASP, 2017). Além desses, o policial deve estar familiarizado com um relevante tratado regional sobre Direitos Humanos, a Convenção Americana de Direitos Humanos, também conhecida como Pacto de São José da Costa Rica, aderida pelo Brasil em 25 de setembro de 1992 (SENASP, 2017).

O artigo $1^{\circ}$ da Constituição da República Federativa do Brasil, de 1988 (CRFB/1988), versa sobre os princípios fundamentais, constituindo, em seu caput, o Brasil como um Estado Democrático de Direito e apresenta os seus fundamentos, dentre eles, no inciso III, o da dignidade da pessoa humana (BRASIL, 1988). Já o artigo $5^{\circ}$ da CRFB/88 versa sobre os direitos e garantias fundamentais, tendo, em seu inciso LXXVIII, parágrafos $2^{\circ}$ e $3^{\circ}$, o seguinte: 
Necropolítica no Estado do Rio de Janeiro.

Revista Ensaios, vol. 15, jul-dez de 2019.

\begin{abstract}
$\S 2^{\circ}$ Os direitos e garantias expressos nesta Constituição não excluem outros decorrentes do regime e dos princípios por ela adotados, ou dos tratados internacionais em que a República Federativa do Brasil seja parte.

$\S 3^{\circ}$ Os tratados e convenções internacionais sobre direitos humanos que forem aprovados, em cada Casa do Congresso Nacional, em dois turnos, por três quintos dos votos dos respectivos membros, serão equivalentes às emendas constitucionais. (BRASIL, 1988).
\end{abstract}

Assim, os tratados internacionais, dos quais o Brasil faz parte, são considerados emendas constitucionais e estão acima, no ordenamento jurídico brasileiro, das leis, decretos e portarias.

\title{
3) Método:
}

A pesquisa é de abordagem quali-quantitativa. Utilizou-se a estatística descritiva e inferencial para analisar quantitativamente a relação entre os homicídios por intervenção policial e homicídios dolosos no Estado do Rio de Janeiro, compilando-se a quantidade absoluta dessas variáveis por semestre, de 1998 até o primeiro semestre de 2019. Como instrumento, utilizou-se o Excel ${ }^{\circledR}$ para formatar a tabela, construir o gráfico e fazer a análise de dados por meio de regressão simples. Qualitativamente, foi utilizado o método de análise de discurso para comparar o discurso de morte como política de segurança pública do governador Wilson Witzel à luz da bibliografia Necropolítica (MBEMBE, 2016) e dos direitos humanos, utilizando-se a legislação internacional e nacional sobre o tema e sobre o procedimento policial na utilização do uso da força, sobretudo da arma de fogo.

\section{1) Análise de Dados e Discussão dos Resultados:}

A fim de analisar se a diminuição, no primeiro semestre de 2019, dos homicídios dolosos têm relação com o aumento dos homicídios provenientes de intervenção policial, consultamos os dados do Instituto de Segurança Pública (ISP), desde 1998, e o compilamos por semestre na Tabela 1. conforme o Anexo A.

Do exposto na Tabela 1, elaboramos o gráfico de dispersão com as variáveis homicídio por intervenção policial (variável explanatória) e homicídio doloso (variável resposta). Assim, consideramos a hipótese nula $\left(\mathrm{H}_{0}\right)$ - a não existência de relação entre 
Necropolítica no Estado do Rio de Janeiro.

Revista Ensaios, vol. 15, jul-dez de 2019.

variação de homicídios por intervenção policial e homicídios dolosos -, e a hipótese alternativa $\left(\mathrm{H}_{1}\right)$ - a existência de relação entre variação de homicídios por intervenção policial e homicídios dolosos. Veja a Figura 1.

Gráfico 1 - Série histórica semestral de homicídios de 1998 até o $1^{\circ}$ semestre de 2019.

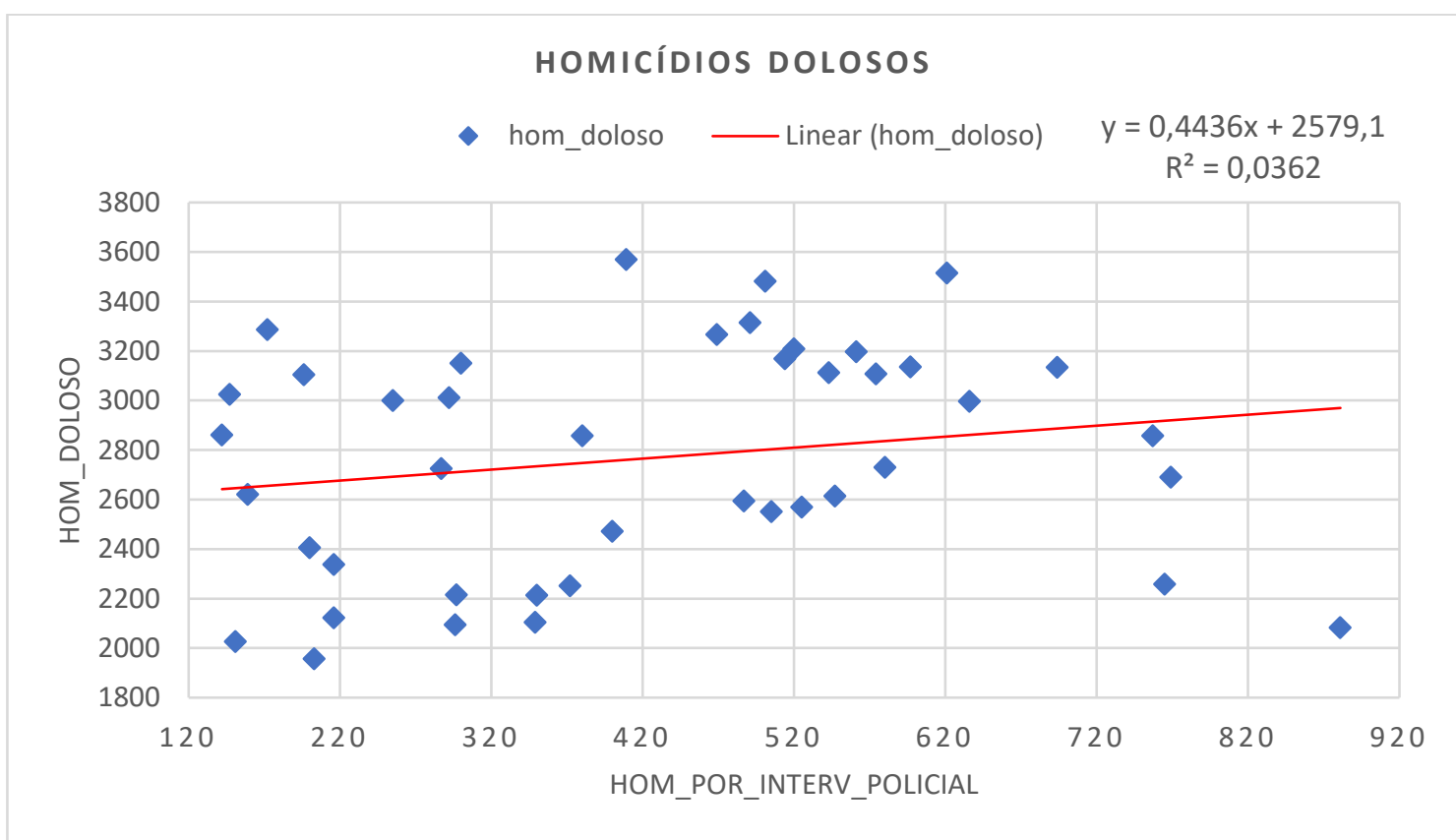

Fonte: Elaboração própria (2019), utilizando dados do ISP. Disponível em: http://www.ispdados.rj.gov.br/estatistica.html. Acesso em: 11 ago. 2019.

Conforme pode ser observado no gráfico de dispersão, a correlação entre homicídios por intervenção policial e homicídios dolosos é positiva e desprezível, pois o cálculo do coeficiente de correlação de Pearson foi $\mathrm{R}=0,190328$, ou seja, tem uma associação linear muito fraca. Observando a reta de regressão na Figura 1, percebemos que a variação dos homicídios dolosos aumenta levemente com o aumento dos homicídios por intervenção policial, tendo um coeficiente de determinação $\mathrm{R}^{2}=0,0362$, isto é, os homicídios por intervenção policial explicariam 3,62\% do aumento dos homicídios dolosos. No entanto, devemos rejeitar esse modelo de regressão simples $(y=0,4436 x+$ 2579,1) devido aos resultados expostos na Figura 2. 
Necropolítica no Estado do Rio de Janeiro.

Revista Ensaios, vol. 15, jul-dez de 2019.

Figura 2 - Resumo dos Resultados da Regressão Simples

RESUMO DOS RESULTADOS

\begin{tabular}{lr}
\hline \multicolumn{2}{c}{ Estotistica de regressāo } \\
\hline A maltiplo & 0,1903284 \\
R-Quadrado & 0,0362249 \\
R-quadrado ajustado & 0,0127182 \\
Erro padräo & 454,53352 \\
Observaçöes & 43 \\
\hline
\end{tabular}

Observachoes

\begin{tabular}{lrrrrrr}
\hline ANOVA & \multicolumn{1}{c}{ Sa } & MQ & $F$ & Fde significoçäo \\
\hline Regressbo & 1 & 318380,9 & 318381 & 1,54104 & 0,22151787 \\
Residuo & 41 & 8470629,6 & 206601 & & \\
Total & 42 & 8789010,5 & & & \\
\hline
\end{tabular}

Coeficientes Erro padräa Stat t valor-P 95\% inforiores 95\% superiares inferiar 95,09\% \$uperior 95, 0\%

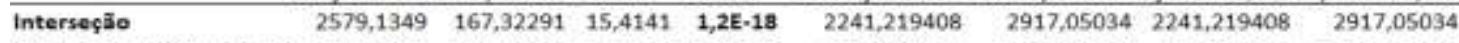
\begin{tabular}{lllllllll} 
hom_por_interv_polieial & 0,4435884 & 0,3573325 & 1.24139 & 0,22152 & $-0,278059334$ & 1,165236068 & $-0,27805933$ & 1.165236068 \\
\hline
\end{tabular} Fonte: Elaboração própria (2019), utilizando dados do ISP. Disponível em: http://www.ispdados.rj.gov.br/estatistica.html. Acesso em: 11 ago. 2019.

Interpretando os dados da regressão simples (Figura 2), observamos pelo teste de significância individual, que não devemos rejeitar a $\mathrm{H}_{0}$, já que o valor-p =0,221518, ou seja, não é significante, uma vez que é > 0,05. Assim, não rejeitamos a $\mathrm{H}_{0}$, isto é, a evidência estatística é de inexistência de relação entre variação de homicídios por intervenção policial e homicídios dolosos.

Da análise estatística, afirma-se que, com 95\% de confiança, a redução dos homicídios dolosos, no primeiro semestre de 2019, não está relacionada ao aumento dos homicídios por intervenção policial. Logo, estatisticamente, a necropolítica adotada como política de segurança pública, pelo governador Wilson Witzel, não é eficaz na redução de homicídios dolosos no Estado do Rio de Janeiro.

Além disso, o discurso de morte adotado pelo governador Wilson Witzel é contrário à filosofia dos direitos humanos aplicada à atuação policial e aos procedimentos legais de atuação policial. Por exemplo, quando ele diz que:

- Na vida não tem atalho. É muito estudo, e muito trabalho. Agora, o vagabundo, aquele que é bandido, quer atalho. Aí, nós, que somos cidadãos, não vamos aceitar isso. A nossa Polícia Militar não quer matar, mas não podemos permitir cenas como aquela que nós vimos na Cidade de Deus. Se fosse com autorização da ONU, em outros lugares do mundo, nós teríamos autorização para mandar um míssil naquele local e explodir aquelas pessoas (LEAL, 2019).

Percebemos que o governador discursa contra o Estado Democrático de Direito, um princípio fundamental garantido pelo artigo $1^{\circ}$ da CRFB/88 que, inclusive, também 
Necropolítica no Estado do Rio de Janeiro.

Revista Ensaios, vol. 15, jul-dez de 2019.

versa sobre a dignidade da pessoa humana, um direito assegurado em vários tratados de direitos humanos, além de ferir os princípios básicos do Direito Humanitário Internacional (DHI). Com esse discurso, o governador Witzel também ignora a alínea a), inciso XLVII, artigo $5^{\circ}$ da CRFB/88 que veda a pena de morte, salvo em tempo de guerra, declarada pelo Presidente da República e autorizada pelo Congresso Nacional, ou seja, em estado de guerra, que é um estado de exceção. Estado este que o governador, à revelia da Constituição Federal, tenta usar para justificar a sua política de morte quando diz que:

— Nós estamos vivendo um estado de terrorismo, não no Estado do Rio como
um todo, mas nas comunidades em que eles (traficantes) se infiltram. Não é a
comunidade que faz o sujeito ser terrorista, porque lá na Cidade de Deus, lá na
Rocinha, tem gente decente, que trabalha, que estuda. (LEAL, 2019).

Esse discurso se alinha com o que Mbembe já nos alertara de que "[...] o estado de exceção e a relação de inimizade tornaram-se a base normativa do direito de matar" (MBEMBE, 2016, p. 128), e como o poder “[...] apela à exceção, emergência e a uma noção ficcional do inimigo" (MBEMBE, 2016, p. 128) a fim de justificar o extermínio de outrem, no qual o traficante é o inimigo a ser morto e as comunidades - favelas - são as colônias semelhantes às fronteiras, habitadas por "selvagens", em um processo de desumanização do "inimigo" - traficante (MBEMBE, 2016).

Todo esse discurso de matar o criminoso que estiver armado, sobretudo de fuzil, sem que este ofereça resistência à prisão, fere os direitos humanos garantidos pelo direito internacional e nacional. O artigo 284 do Código de Processo Penal Brasileiro diz que "não será permitido o emprego de força, salvo a indispensável no caso de resistência ou de tentativa de fuga do preso" (BRASIL, 1941). Este emprego da força deve seguir protocolos, como os previstos na Portaria Interministerial n. ${ }^{\circ} 4.226$, de 31 de dezembro de 2010, que estabelece diretrizes sobre o uso da força por agentes de segurança pública e teve como referência um importante instrumento de direitos humanos da ONU, o Código de Conduta para Funcionários Responsáveis pela Aplicação da Lei (ONU, 1979). $\mathrm{O}$ artigo $3^{\circ}$ do supracitado código estabelece que os policiais só poderão usar a força em caso de extrema necessidade e apenas na medida para o cumprimento do dever (ONU, 1979). Sobre o uso de arma de fogo, a alínea c), do artigo $3^{\circ}$, do referido código de conduta, estabelece que: 
Necropolítica no Estado do Rio de Janeiro.

Revista Ensaios, vol. 15, jul-dez de 2019.

c) O emprego de armas de fogo é considerado uma medida extrema. Devem fazer-se todos os esforços no sentido de excluir a utilização de armas de fogo, especialmente contra as crianças. Em geral, não deverão utilizar-se armas de fogo, excepto quando um suspeito ofereça resistência armada, ou quando, de qualquer forma coloque em perigo vidas alheias e não haja suficientes medidas menos extremas para o dominar ou deter. Cada vez que uma arma de fogo for disparada, deverá informar-se prontamente as autoridades competentes. (ONU, 1973).

Assim, é visível que o discurso de morte utilizado pelo governador Wilson Witzel é contrário à legislação internacional e nacional para o emprego de arma de fogo pelos policiais.

\section{4) Considerações finais:}

Diante do exposto, podemos observar que a política pública de morte, ou necropolítica, aplicada à segurança pública do Estado do Rio de Janeiro pelo governador Wilson Witzel é ineficaz e ineficiente. É ineficaz porque, quantitativamente, os homicídios por intervenção policial não reduzem os homicídios dolosos praticados no RJ, conforme foi demonstrado estatisticamente por meio da fraca correlação entre essas variáveis (Figura 1) e de teste de modelo de regressão simples (Figura 2). É ineficiente porque não segue os protocolos legais internacionais e nacionais sobre o emprego da força, sobretudo de arma de fogo, pelos policiais, desrespeitando tratados internacionais de direitos humanos, a Constituição Federal e normas infraconstitucionais.

Qualitativamente, a necropolítica no Estado do Rio de Janeiro fere a dignidade da pessoa humana, ao tratar as favelas fluminenses como colônias fronteiriças, submetendo os seus moradores às frequentes operações policiais que culminam em confrontos armados entre as polícias e criminosos, acarretando inocentes mortos, o chamado efeito colateral, e desumanizando tais criminosos, que são vistos como selvagens a serem abatidos, inimigos em um estado de exceção ilegal perpetrado pelo governador, que classifica os criminosos como inimigos desprovidos de direitos humanos e, sem a dignidade da pessoa humana, de suas próprias humanidades.

Recebido 21/08/2019. Aprovado 05/05/2020 
Necropolítica no Estado do Rio de Janeiro.

Revista Ensaios, vol. 15, jul-dez de 2019.

\section{Referências bibliográficas:}

ABDALA, Vitor. Comissão da Alerj denuncia Witzel à OEA por política de segurança. Agência Brasil. Rio de Janeiro, 05 mai. 2019. Disponível em: http://agenciabrasil.ebc.com.br/geral/noticia/2019-05/comissao-da-alerj-denunciawitzel-oea-por-politica-de-seguranca. Acesso em: 10 ago. 2019.

AGAMBEN, Giorgio. Moyens sans fins: notes sur la politique. Paris: Payot \& Rivages, 1995.

BELO, Eduardo. Consumo de moradores de favelas no Brasil supera R \$ 68 bilhões ao ano. Valor Econômico, São Paulo, 02 mar. 2015. Disponível em: https://www.valor.com.br/empresas/3932544/consumo-de-moradores-de-favelas-nobrasil-supera-r-68-bilhoes-ao-ano/. Acesso em: 10 ago. 2019.

BRASIL. Constituição (1988). Constituição da República Federativa do Brasil. Brasília, DF: Senado, 1988.

Decreto-Lei n. ${ }^{\circ}$ 3.689, de 3 de Outubro de 1941. Código de Processo Penal. Disponível em: http://www.planalto.gov.br/ccivil_03/decreto-lei/del3689.htm. Acesso em: 10 ago. 2019.

IBGE. Instituto Brasileiro de Geografia e Estatística. Projeções e estimativas da população do Brasil e das Unidades da Federação. População. Disponível em: https://www.ibge.gov.br/apps/populacao/projecao/. Acesso em: 10 ago. 2019.

EILBAUM, Lucía; MEDEIROS, Flavia. "Quando existe 'violência policial'? Direitos, moralidades e ordem pública no Rio de Janeiro". In: DILEMAS: Revista de Estudos de Conflito e Controle Social, v. 8, n. 3, JUL/AGO/SET 2015 - pp. 407-428.

ELIAS, Norbert. "Processos de formação de Estados e construção de nações". In:

Escritos \& ensaios; 1: Estado, processo, opinião pública. Organização e apresentação Federico Neiburg e Leopoldo Waizbort. Rio de Janeiro: Jorge Zahar Ed. p.153-165, 2006.

FOUCAULT, Michel. Em Defesa da Sociedade. São Paulo, Ed. Martins Fontes, 2005.

"O sujeito e o poder". In: Hubert L. Dreyfus e Paul Rabinow. MICHEL FOUCAULT. Uma Trajetória Filosófica. Para além do estruturalismo e da hermenêutica. Coleção Biblioteca de Filosofia. Coordenação editorial: Roberto Machado. Rio de Janeiro: Forense Universitária, 2009.

G1. Seis jovens são mortos em ações da polícia em cinco dias no RJ. [S. 1.: s. n.], 14 ago. 2019. 1 vídeo (06 min $23 \mathrm{seg}$ ). Globo News. Disponível em: http://g1.globo.com/globonews/videos/v/seis-jovens-sao-mortos-em-acoes-da-policia-em-cinco-dias-norj/7843394/. Acesso em: 15 ago. 2019.

LEAL. Arthur. Witzel causa polêmica ao falar em 'mandar míssil' para explodir traficantes na Cidade de Deus. O Globo Rio. Rio de Janeiro, 14 jun. 2019. Disponível em: https://oglobo.globo.com/rio/witzel-causa-polemica-ao-falar-em-mandar-missilpara-explodir-traficantes-na-cidade-de-deus-23741965. Acesso em: 10 ago. 2019. 
Necropolítica no Estado do Rio de Janeiro.

Revista Ensaios, vol. 15, jul-dez de 2019.

MBEMBE, Achille. Necropolítica. Arte \& Ensaios, v. 2, n. 32, dez. 2016. Disponível em: https://revistas.ufrj.br/index.php/ae/article/view/8993/7169. Acesso em 11 ago. 2019.

MEIRELLES, Renato; ATHAYDE, Celso. Um país chamado favela: a maior pesquisa já feita sobre a favela brasileira. 2014. São Paulo: Gente, 167p.

MELLO, Igor. Polícia mata 1 a cada 5 horas e responde por $30 \%$ das mortes violentas no RJ. UOL, no Rio. Rio de Janeiro, 22 jul. 2019. Disponível em: https://noticias.uol.com.br/cotidiano/ultimas-noticias/2019/07/22/com-semestre-maisletal-da-historia-policia-mata-a-cada-5-horas-norio.htm?fbclid=IwAR3tHrhy_rW17KNy9WzURhGe8AZMgTDHSIJie45AAUHFZbbGcwByJq8Rps. Acesso em: 10 ago. 2019.

NA LATA. NALATA com WILSON WITZEL (Governador do Estado do RJ). [S. 1.: s. n.], 05 ago. 2019. 1 vídeo (39 min $30 \mathrm{seg}$ ). Publicado pelo canal Na Lata com Antonia Fontenelle. Disponível em: https://www.youtube.com/watch?v=9DrsvVfn94A. Acesso em: 10 ago. 2019.

ONU. Organização das Nações Unidas. Código de Conduta para os Funcionários Responsáveis pela Aplicação da Lei, de 17 de Dezembro de 1979. Disponível em: http://www.dhnet.org.br/direitos/sip/onu/ajus/prev18.htm. Acesso em: 20 ago. 2019.

O GLOBO. 'Se tiver de arma na mão, tem que morrer', diz Wilson Witzel. [S. 1.: s. n.], 04 nov. 2018. 1 vídeo (13 $\mathrm{min} 14 \mathrm{seg}$ ). Publicado pelo canal Jornal O Globo. Disponível em: https://www.youtube.com/watch?v=CLfGH8MU4d8. Acesso em: 10 ago. 2018.

ROVER, Cees De. Para servir e proteger. Direitos humanos e direito internacional humanitário para forças policiais e de segurança: manual para instrutores. Trad. Sílvia Backes e Ernani S. Pilla. 4.ed. Comitê Internacional da Cruz Vermelha. Brasília DF 2005.

SENASP. Secretaria Nacional de Segurança Pública. Filosofia dos Direitos Humanos Aplicada à Atuação Policial. Brasília, 2017. (Apostila).

TV BRASIL. Wilson Witzel defende política de matar criminosos armados. [S. 1.: s. n.], 22 jul. 2019. 1 vídeo (1 min $58 \mathrm{seg}$ ). Publicado pelo canal TV Brasil. Disponível em: https://www.youtube.com/watch?v=29D-C3h99qc. Acesso em: 10 ago. 2019.

VEJA. Wilson Witzel: 'A polícia vai mirar na cabecinha e... fogo'. Política. [S. 1.: s. n.], 01 nov. 2018. Disponível em: https://veja.abril.com.br/politica/wilson-witzel-a-policiavai-mirar-na-cabecinha-e-fogo/. Acesso em: 10 ago. 2018. 